$\underline{\text { Case Reports }}$

\title{
Bacillus Cereus Catheter Related Bloodstream Infection in a Patient with Acute Lymphoblastic Leukemia
}

\author{
N Gurler ${ }^{1}$, L Oksuz $^{1}$, M Muftuoglu $^{2}$, FD Sargin ${ }^{2}$ and SK Besisik ${ }^{2}$ \\ ${ }^{1}$ Istanbul University, Istanbul Medical Faculty, Department of Medical Microbiology, Capa-Istanbul Turkey \\ ${ }^{2}$ Istanbul University, Istanbul Medical Faculty, Department of Haematology, Capa-Istanbul Turkey
}

Correspondence to: Dr Lütfiye Öksüz. Istanbul University, Istanbul Medical Faculty, Department of Medical Microbiology, Capa-Istanbul Turkey. E-mail: loksuz34@yahoo.com

Competing interests: The authors have declared that no competing interests exist.

Published: Jabuary 18, 2012

Received: November 1, 2011

Accepted: December 23, 2011

Citation: Mediterr J Hematol Infect Dis 2012, 4(1): e2012004, DOI: 10.4084/MJHID.2012.004

This article is available from: http://www.mjhid.org/article/view/9482

This is an Open Access article distributed under the terms of the Creative Commons Attribution License (http://creativecommons.org/licenses/by/2.0), which permits unrestricted use, distribution, and reproduction in any medium, provided the original work is properly cited.

Abstract. Bacillus cereus infection is rarely associated with actual infection and for this reason single positive blood culture is usually regarded as contamination. However it may cause a number of infections, such catheter-related bloodstream infections. Significant catheter-related bloodstream infections (CRBSI) caused by Bacillus spp. are mainly due to B. cereus and have been predominantly reported in immunocompromised hosts. Catheter removal is generally advised for management of infection. In this report, catheter-related bacteremia caused by $\boldsymbol{B}$. cereus in a patient with acute lymphoblastic leukemia (ALL) in Istanbul Medical Faculty was presented.

Case. A 44-year old man presented with fatigue, weight loss, epistaxis and high fever. Physical examination was insignificant except for pallorness, Complete blood count revealed total white blood cells at $130,000 / \mathrm{mm}^{3}$ hemoglobin at $7.6 \mathrm{~g} / \mathrm{dl}$, platelet $30,000 / \mathrm{mm}^{3}$. He was diagnosed with Pre-B acute lymphoblastic leukemia following bone marrow aspiration, biyopsy and flow cytometric analysis. Cytogenetic analysis showed a karyotype of $45, \mathrm{XY}$ del 9 del 16. The patient achieved complete hematological remission accompanied by disappearance of cytogenetic abnormalities following induction chemotherapy with BFM ALL protocol. The patient was considered to be a candidate for stem cell transplantion because of initial patient characteristics indicating high risk for ALL relapse (Age, complex clonal cytogenetic abnormalities, high total leukocyte count). An HLA-identical unrelated donor, living abroad, was identified. A double-lumen Hickmancatheter (Bard 12.0 Fr, Round Dual Lumen) was inserted by surgical cut-down to access the right subclavian vein which would be necessary for allogeneic stem cell transplantation. Two cycles of consolidation chemotherapy were administered before proceeding to stem cell transplantation. Three weeks later central nervous system (CNS) relapse of ALL occurred, which is treated with four cycles of intrathecal chemoterapy, comprising of methotrexate, cytosine arabinoside and dexamethasone. At the same time a cycle of cytosine arabinoside and cyclophosphamide-based chemotherapy was administered. Stem cell transplantation was planned to be carried out in a month. Three weeks later the patient presented with high fever and headache. Blood cultures 
were obtained from the catheter and from a peripheral vein and evaluated on the BACTEC 9120 system (Becton Dickinson, USA). Bacillus spp. was isolated from the cathether while blood culture obtained from the peripheral vein remained negative. It was regarded as contaminant so that complete identification of Bacillus species was not carried out. Lumbar puncture was performed and CNS involvement was documented. Lymphoblastic cells were seen on peripheral blood smear which is considered compatible with hematological relapse. Intrathecal chemotherapy, and methotrexate and high-dose cytosine arabinosidebased systemic reinduction chemotherapy were started. One week after chemotherapy he developed chills and high fever as absolute neutrophil count was $100 / \mathrm{mm}^{3}$. The physical examination was noncontributary and blood cultures were collected from the catheter and a peripheral vein. Two blood culture bottles (one from the catheter and one from the peripheral) were positive gram-positive bacilli after three days of incubation at $35^{\circ} \mathrm{C}$. The organism produced large, greenish colonies. The bacterium was identified as B.cereus on the basis of Gram staining, colony morphology, motility, lecitinase activity. The bacterial identification was confirmed as B.cereus using VITEK identification system (bioMeriéux, France). The strain was sensitive to imipenem, vancomycin, gentamicin and ciprofloxacin, whereas resistant to penicillin, cephalosporins and co-trimoxazole. He was started on piperacillin-tazobactam at a dose of $4 \mathrm{~g} / 500 \mathrm{mg}$ every $6 \mathrm{~h}$ emprically before blood culture result was available. Vancomycin was added to the treatment regimen due to incomplete clinical and laboratory response. Hickmann catheter, which was inserted about ten months ago, was accepted as the focus of infection and, prolonged maintenance of the catheter was thought to be no more possible. High fever subsided completely upon removal. Hematological remission was achieved and allogeneic stem cell transplantation was scheduled to be performed one week later.

Conclusion. Bacillus species are known to be responsible for several systemic infections, especially in immunocompromised patients. The most commonly reported systemic infection is bacteremia. ${ }^{2,3}$ Bacillus bacteremia can be serious and even fatal, in immunocompromised patients, such as neutropenia. The most common feature in true Bacillus bacteremia is the presence of an intravascular catheter. B. cereus produce biofilms, which can play a major role in attachment to catheters. ${ }^{10}$ Bacillus species are associated with CRBSIs and they have been well documented, especially among patients with hematological malignancies. ${ }^{10,22}$ Some of the reported cases in the literature were shown in the table $\mathbf{1}$. The table shows that the majority of the patients have abdominal symptoms, but our patients not.

The isolation of Bacillus species raises the possibility of contamination on the basis of Bacillus spp. being common contaminants of blood cultures. ${ }^{8}$ The ability of Bacillus spp to form a biofilm matrix and the adherence properties account for their relation with central venous catheter (CVC) infections. ${ }^{4}$ Catheterrelated Bacillus spp infections are difficult to eradicate because of slime formation and biofilm production on the catheter surface. Most published data are based on small case series and data regarding the management of Bacillus spp. infections are still lacking. Recently conducted study, which is currently the largest series reported, has concluded that retention of the catheter beyond 72 hours after the onset of bacteremia was related to a higher incidence of recurrent Bacillus bacteremia. ${ }^{2}$ The drug of choice for Bacillus infections is vancomycin. ${ }^{5}$ Despite the proper agent and appropriate length of treatment the clinical outcome remains unsatisfactory. This is largely due to inactivity of vancomycin against the organisms dwelling in biofilm layer and slime production,making the organism highly adherent to the catheters. Based on preliminary data and available "Infectious Diseases Society of America (IDSA)" guideline early catheter removal should be the cornerstone of Bacillus bacteremia management. ${ }^{2,6,7}$ In compatible with this report, our patient developed intermittent fever spikes under the appropriate antimicrobial therapy even though neutropenia resolved with G-CSF support. The Hickmann catheter was removed on the $10^{\text {th }}$ day of vancomycin therapy. Septicemia-related thrombocytopenia unresponsive to aggressive thrombocyte transfusion hindered early removal of the catheter. Catheter tip culture remained negative, which is attributed to ongoing antibiotherapy consisting of piperacillin-tazobactam and vancomycin.

According to the IDSA guidelines published in $2009,{ }^{6}$ Bacillus CRBSIs should be considered after blood contamination is ruled out on the basis of multiple positive culture results, with at least one blood culture sample obtained from a peripheral vein. It is also suggested that the catheters should be removed if the diagnosis is certain, except for in patients having uncomplicated CRBSI involving long-term catheters because of limited access sites and requiring long-term vascular access for survival.

Bacillus cereus is a growing concern as a cause of life-threatening infections in patients with hematologic malignancies. ${ }^{9}$ B.cereus should be suspected in immunosuppressed patients with intravascular catheter. B.cereus septicemia may be fatal in immunocompromised hosts despite broad-spectrum appropriate treatment. Catheter removal is essential for 
Table 1. Reported cases of immunsupressed patients with Bacillus cereus bacteremia.

\begin{tabular}{|c|c|c|c|c|c|c|}
\hline Reference & Year & Age & Diagnosis & $\begin{array}{c}\text { Intravenous } \\
\text { catheter }\end{array}$ & $\begin{array}{l}\text { Abdominal } \\
\text { symptoms }\end{array}$ & Outcome \\
\hline 11 & 1988 & 67 & Acute lymphoblastic leukemia & & Present & Death \\
\hline 12 & 1993 & 43 & Acute myelogenous leukemia & Yes & Present & Death \\
\hline 12 & 1993 & 15 & Acute myeloid leukemia & Yes & Present & Death \\
\hline 13 & 1997 & 20 & Acute lymphoblastic leukemia(relapse) & & Present & Death \\
\hline 14 & 1997 & 64 & Acute myeloid leukemia & Yes & Present & Death \\
\hline 13 & 1998 & 10 & Acute lymphoblastic leukemia(relapse) & & Present & Recovery \\
\hline 15 & 1999 & 13 & Acute lymphoblastic leukemia & Yes & Present & Survived \\
\hline 15 & 1999 & 15 & Acute lymphoblastic leukemia(relapse) & Yes & Present & Death \\
\hline 16 & 1999 & 30 & Acute myeloid leukemia & Yes & Present & Death \\
\hline 16 & 1999 & 43 & Acute myeloid leukemia & Yes & Present & Death \\
\hline 16 & 1999 & 14 & Acute lymphoblastic leukemia & Yes & None & Survived \\
\hline 17 & 2002 & 37 & Acute myeloid leukemia & & Present & Recovery \\
\hline 3 & 2003 & 5 & Hemophilia & Yes & None & Recovery \\
\hline 18 & 2005 & 34 & Acute lymphoblastic leukemia & Yes & Present & Death \\
\hline 19 & 2006 & 33 & Biphenotypic acute leukemia & Yes & Present & Death \\
\hline 20 & 2006 & 23 & Acute myeloid leukemia & Yes & Present & Death \\
\hline 20 & 2006 & 34 & Acute lymphoblastic leukemia & Yes & None & Recovery \\
\hline 20 & 2006 & 71 & Acute myeloid leukemia & Yes & None & Recovery \\
\hline 21 & 2008 & 64 & Acute myeloid leukemia & & Present & Death \\
\hline Present case & 2010 & 44 & Acute lymphoblastic leukemia & Yes & None & Recovery \\
\hline
\end{tabular}

prevention of recurrent bacteremia. Long-term catheter salvage should be reserved for appropriate patient group.

\section{References:}

1. Leonidou L, Gogos CA. Catheter-related bloodstream infections: catheter management according to pathogen. Int $\mathrm{J}$ Antimicrob Agents 2010; 36: Kassar R, Hachem R, Jiang Y, Chaftari AM, Raad I. Management of Bacillus bacteremia: the need for catheter removal. Medicine (Baltimore) 2009; 88: 279-283.

2. Srivaths PR, Rozans MK, Kelly E Jr, Venkateswaran L. Bacillus cereus central line infection in an immunocompetent child with hemophilia. J Pediatr Hematol Oncol. 2004; 26: 194-196 http://dx.doi.org/10.1097/00043426-200403000-00010 PMid:15125613

3. Branda SS, Chu F, Kearns DB, Losick R, Kolter R. A major protein component of the Bacillus subtilis biofilm matrix. Mol Microbiol 2006;59: 1229-1238. http://dx.doi.org/10.1111/j.13652958.2005.05020.x PMid:16430696

4. Cotton DJ, Gill VJ, Marshall DJ, Gress J, Thaler M, Pizzo PA. Clinical features and therapeutic interventions in 17 cases of Bacillus bacteremia in an immunosuppressed patient population. $\mathrm{J}$ Clin Microbiol 1987; 25: 672-674. PMid:3571476 PMCid:266057

5. Mermel LA, Allon M, Bouza E, Craven DE et al. Clinical practice guidelines for the diagnosis and management of intravascular catheter-related infection: 2009 update by the Infectious Diseases Society of America. Clin Infect Dis 2009; 49: 1-45. http://dx.doi.org/10.1086/599376 PMid:19489710

6. Park HG, Choi SH. Long-term central venous catheter salvage in patients with Bacillus bacteremia. Medicine. 2010; 89: 346; 347.

7. Weber DJ, Saviteer SM, Rutala WA, Thomann CA. Clinical significance of Bacillus species isolated from blood cultures. South Med J 1989; 82: 705-9. http://dx.doi.org/10.1097/00007611198906000-00008 PMid:2499933
Acknowledgments. This work was supported by Scientific Research Projects Coordination Unit of Istanbul University. Project number 14413.
8. Inoue D, Nagaj Y, Mori M et al. Fulminant sepsis caused by Bacillus cereus in patients with hematologic malignancies: analysis of its prognosis and risk factors. Leuk Lymphoma 2010; 51: 860869. http://dx.doi.org/10.3109/10428191003713976

9. Bottone EJ. Bacillus cereus, a volatile human pathogen. Clin Microb Rev 2010; 23: 382-398. http://dx.doi.org/10.1128/CMR.00073-09 PMid:20375358 PMCid:2863360

10. Funada $\mathrm{H}$, Uatoni $\mathrm{C}$, Machi $\mathrm{T}$, et al. Bacillus cereus bacteremia in an adult with acute leukemia. Jpn J Clin Oncol 1988; 18: 69-74. PMid:3127617

11. Yoshida H, Moriyama Y, Tatekawa T, Tominaga N, Teshima H, et al. Two cases of acute myelogenous leukemia with Bacillus cereus bacteremia resulting in fatal intracranial hemorrhagie. Rinsho Ketsueki 1993; 34: 1568-72. PMid:8295331

12. Arnaout MK, Tamburro RF, Bodner SM, et al. Bacillus cereus causing fulminant sepsis and hemolysis in two patients with acute leukemia. J Ped Hematol/Oncol 1999; 21: 431-435.

13. Akiyama N, Mitani K, Tanaka Y, Hanazano Y, et al. Fulminant septisemic syndrome of Bacillus cereus in a leukemic patient. Int Med 1997; 36: 221-226. http://dx.doi.org/10.2169/internalmedicine.36.221 PMid:9144019

14. Gaur AH, Patrick CC, Mc Cullers JA, Flynn PM; et al. Clin Infect Dis 2001; 32: 1456-1462. http://dx.doi.org/10.1086/320154 PMid:11317247

15. Musa OM, Douri MA, Khan S, Shafi T, et al. Fulminant septicaemic syndrome of Bacillus cereus: Three case reports. J Infect 1999; 39: 154-156. http://dx.doi.org/10.1016/S01634453(99)90009-9 
16. Le Scannf J, Mohammedi I, Thie baut A, Martin O, Argaud L, Robert D. Necrotizing gastritis due to Bacillus cereus in an immunocompromised patient. Infection 2006; 34: 98-99. PMid:16703301

17. Cone LA, Dreisbach L, Potts BE, Comess BE, Burleigh WA. Fatal Bacillus cereus endocarditis masquerading as an anthrax-like infection in a patient with acute lymphoblastic leukemia: case report. J Heart Valve Dis 2005; 14: 37-39. PMid:15700434

18. Kiyomizu K, Yagi T, Yoshida H, Minami R, et al. Fulminant septicemia of Bacillus cereus resistant to carbapenem in a patient with biphenotypic acute leukemia. J Infect Chemother 2008; 14: 361-367. PMid:18936889

19. Ozkocaman V, Ozcelik T, Ali R, Ozkalemkas F, et al. Bacillus spp.
Among hospitalized patients with haematological malignancies: clinicial features, epidemics and outcomes. J Hosp Infect 2006; 64: 169-176. http://dx.doi.org/10.1016/j.jhin.2006.05.014

PMid:16891037

20. Kawatani E, Kishikawa Y, Sankoda C, Kuwahara N, et al. Bacillus cereus sepsis and subarachnoid hemorrhage following consolidation chemotherapy for acute myelogenous leukemia. Rinsho Ketsueki 2009; 50: 300-303. PMid:19404024

21. Fekete T. Bacillus species and related genera other than Bacillus anthracis. Mandell G, Bennet JE, Dolin R (Eds): Mandell, Douglas and Bennett's Principle's and Practice of Infectious Diseases, 7th edition, Chapter 209, p.2727, Philadelphia, Elsevier/Churchill Livingstone, 2010. 